\title{
Low fish intake is associated with low blood concentrations of vitamin D, choline and $n-3$ DHA in pregnant women
}

\author{
Brian T. Wu ${ }^{1,2}$, Roger A. Dyer ${ }^{1}$, D. Janette King $^{1}$ and Sheila M. Innis ${ }^{1,2 *}$ \\ ${ }^{1}$ Department of Paediatrics, Faculty of Medicine, Nutrition and Metabolism Program, Child and Family Research Institute, \\ BC, Canada V5Z 4 H4 \\ ${ }^{2}$ Department of Foods, Nutrition and Health, Faculty of Land and Food Systems, University of British Columbia, \\ Vancouver, BC, Canada V6T 124 \\ (Submitted 7 November 2011 - Final revision received 16 April 2012 - Accepted 24 April 2012 - First published online 12 June 2012)
}

\begin{abstract}
Several studies have investigated the potential health benefits, including those associated with neurological function, of the $n$ - 3 fatty acid DHA. This has arisen in part because of the association between higher intakes of fish, which is a major dietary source of DHA, and reduced disease risk. In addition to DHA, fish also provides choline and vitamin D. The objective of the present study was to assess whether women in the first half of pregnancy with low fish intake also had low blood concentrations of vitamin D, choline and DHA. A total of 222 pregnant women at 16 weeks of gestation were examined for dietary intake, erythrocyte (phosphatidylethanolamine PE) DHA, plasma free choline and 25-hydroxyvitamin D (25(OH)D). Women who consumed $\leq 75 \mathrm{~g}$ fish/week ( $n$ 56) compared to $\geq 150 \mathrm{~g}$ fish/week ( $n$ 116) had lower dietary intake of DHA, total choline and vitamin D $(P<0 \cdot 001)$, and lower erythrocyte PE DHA (5.25 (SD 1.27 ), 6.83 (SD 1.62$) \mathrm{g} / 100 \mathrm{~g}$ total fatty acid, respectively, $P<0.01$ ), plasma free choline (6.59) (SD 1.65 ), 7.40 (SD 2.05$) \mu \mathrm{mol} / 1$, respectively, $P=0.023)$ and $25(\mathrm{OH}) \mathrm{D}(50 \cdot 3(\mathrm{sD} 20 \cdot 0), 62 \cdot 5(\mathrm{sD} 29 \cdot 8) \mathrm{nmol} / 1$, respectively, $P<0 \cdot 01)$. DHA intake was positively related to the intake of vitamin D from foods $(\rho 0.47, P<0.001)$ and total choline $(\rho 0.32, P<0 \cdot 001)$. Dietary intakes and biomarkers of DHA, choline and vitamin D status were assessed to be linked. This raises the possibility that unidentified concurrent nutrient inadequacies might have an impact on the results of studies addressing the benefits of supplemental DHA.
\end{abstract}

Key words: Dietary fish: DHA: Vitamin D: Choline

Epidemiological studies have reported a positive association between the intakes of finfish and other seafoods and a lower risk of several diseases, including CVD and some neurological disorders ${ }^{(1-10)}$. Fish is a major source of the $n$-3 fatty acid DHA, which is a precursor of proresolving anti-inflammatory mediators, a ligand for transcription factors that regulate lipid metabolism, and contributes to the regulation of cardiac muscle ion channel activities in addition to other functions ${ }^{(11-13)}$. Furthermore, several studies have reported a positive association between higher intakes of fish during pregnancy and better child neurodevelopment outcome $\mathrm{e}^{(14-18)}$. However, fish is a source of other nutrients in addition to DHA, raising the possibility that some individuals with low fish intakes may be limiting in other nutrients. Among these nutrients, vitamin $\mathrm{D}$ is particularly relevant since fish is one of the few natural food sources of this vitamin. Increased risk of poor vitamin D status has been documented among pregnant women in northern latitudes, with the risk of deficiency modified by season and race, regardless of current food fortification and other vitamin D supplementation strategies ${ }^{(19-24)}$. Importantly, maternal blood levels of 25-hydroxyvitamin D $(25(\mathrm{OH}) \mathrm{D})$ in gestation are positively correlated with blood levels of $25(\mathrm{OH}) \mathrm{D}$ in the newborn ${ }^{(25)}$, raising the possibility that maternal vitamin $\mathrm{D}$ insufficiency might adversely have an impact on child development. In this regard, recent studies have shown that vitamin $\mathrm{D}$, via the vitamin $\mathrm{D}$ receptors in the brain, plays key roles in neural development, with functions that include neurite outgrowth, neuro-protective and anti-inflammatory actions, regulation of neuro-trophic factors, and dopaminergic signalling ${ }^{(26-29)}$, all of which are roles in which DHA also functions ${ }^{(30)}$.

Fish is also a rich natural source of choline, which is important in methyl metabolism, membrane phospholipids and sphingolipids, and acetylcholine ${ }^{(31,32)}$. Like vitamin D and $\mathrm{DHA}^{(25,33,34)}$, maternal plasma levels of choline in gestation are positively correlated with plasma choline levels in the newborn ${ }^{(35)}$. In animals, maternal choline deficiency during

Abbreviations: 25(OH)D, 25-hydroxyvitamin D; PE, ethanolamine phospholipids.

*Corresponding author: S. M. Innis, fax +1 604875 3597, email sinnis@mail.ubc.ca 
critical windows of brain development is known to lead to lasting impairments in neural functioning in offspring ${ }^{(36)}$. In the light of the possibility that fish is an important source of several key nutrients important in brain development, the present study assessed whether women in the first half of pregnancy with low compared to higher fish intakes, defined as $\leq 75 \mathrm{~g}$ and $>150 \mathrm{~g}$ fish/week, respectively, have low biomarkers of DHA as well as vitamin D and choline status when assessed using erythrocyte membrane DHA, plasma $25(\mathrm{OH}) \mathrm{D}$ and plasma free choline, respectively.

\section{Methods and materials \\ Subjects}

The present study involved 222 healthy pregnant women, 20-40 years of age, with collection of dietary and sociodemographic information and venous blood at 16 weeks of gestation. The subjects and blood samples were derived from baseline measures of pregnant women enrolled in a prospective study designed to assess the possibility that poor maternal DHA status in gestation adversely affects child development. Women following a vegan diet, taking fish oils or other fatty acid supplements, at risk for preterm infant delivery or any complication likely to make an impact on infant growth and development were not included. From the subjects enrolled, only data for pregnant women who subsequently completed a study visit at 36 weeks' gestation were analysed. Thus, this study does not allow for consideration of adverse dietary or other factors sufficient to result in preterm delivery or pregnancy termination before 36 weeks' gestation. The protocol was approved by the Committee for Ethical Review of Research Involving Human Subjects at the University of British Columbia and the British Columbia's Children's and Women's Hospital. All participants provided written informed consent before participation.

\section{Dietary analyses}

Information on usual dietary intake over the previous month was collected at 16 weeks' gestation using an interview- administered FFQ which included detailed descriptions of ruminant and non-ruminant meats, fatty and lean fish, shellfish, poultry, dairy products, fats and oils, nuts, seeds, vegetables, grains, processed and other foods ${ }^{(37,38)}$. Information on supplement use was recorded, but no measures for assessing daily intake or use of multiple supplements were included. Thus, supplement data were not used in any of our analyses. Most prenatal vitamins in Canada contain $10 \mu \mathrm{g}$ vitamin $\mathrm{D}$, while milk is fortified at $1 \cdot 0-1 \cdot 3 \mu \mathrm{g} / 100 \mathrm{ml}$, and margarine is fortified at $\geq 1.32 \mu \mathrm{g} / 10 \mathrm{~g}^{(39)}$. Nutrient intakes from foods were determined for each subject using nutrient data software (FOOD PROCESSOR 10.8.0; Esha Research) with the Canadian nutrient file, updated to include complete data on $n-6$ and $n-3$ fatty acids in foods. The intakes of choline from foods were determined as the sum of all water and lipid forms of choline, using the USDA database on choline in foods ${ }^{(40)}$.

\section{Blood samples and analytical methods}

Fasting venous blood was collected from each subject in the outpatient laboratory of the British Columbia's Women's and Children's Hospital. The erythrocytes were separated from plasma by centrifugation at $2000 \mathrm{~g}, 15 \mathrm{~min}$ at $4^{\circ} \mathrm{C}$, and the buffy coat removed, following which the erythrocytes were washed two times by resuspension in normal saline, and all samples were stored at $-70^{\circ} \mathrm{C}$ until analysis. For analyses, the erythrocyte total lipids were extracted, then the ethanolamine phospholipids (PE) were separated and the fatty acids analysed by GLC with flame ionisation detection ${ }^{(37)}$. The proportion of DHA in the erythrocyte PE fatty acids was used as a stable measure of DHA status, since PE is predominantly on the cytosolic surface of the erythrocyte membrane bilayer and is more stable to short-term variations in diet than plasma total lipids or the erythrocyte phosphatidylcholine ${ }^{(41)}$. Plasma free choline was analysed using liquid chromatographytandem MS as recently described ${ }^{(42)}$. Plasma $25(\mathrm{OH}) \mathrm{D}$ was analysed with the DiaSorin radioimmunoassay (DiaSorin), which detects $25(\mathrm{OH}) \mathrm{D}_{2}$ and $25(\mathrm{OH}) \mathrm{D}_{3}$ equally.

Table 1. Macronutrient, fatty acid, vitamin $D$ and choline intakes from food for 222 pregnant women at 16 weeks' gestation

(Mean values, standard deviations, medians, interquartile ranges and 5th-95th percentiles)

\begin{tabular}{|c|c|c|c|c|c|}
\hline & Mean & SD & Median & Interquartile range & 5th-95th percentile \\
\hline Carbohydrate (\% en) & 51.5 & $6 \cdot 6$ & 51.5 & $47 \cdot 1-55 \cdot 3$ & $40 \cdot 5-62 \cdot 4$ \\
\hline Protein (\% en) & $17 \cdot 6$ & 2.9 & 17.5 & $15 \cdot 6-19 \cdot 0$ & $13.4-23.0$ \\
\hline Fat (\% en) & 33.8 & $5 \cdot 8$ & $33 \cdot 6$ & $29 \cdot 9-37.4$ & $24 \cdot 4-44 \cdot 5$ \\
\hline Saturated fat (\% en) & $11 \cdot 7$ & $3 \cdot 0$ & $11 \cdot 2$ & $9 \cdot 5-13 \cdot 8$ & $7 \cdot 2-17 \cdot 0$ \\
\hline MUFA (\% en) & $12 \cdot 9$ & $2 \cdot 8$ & $12 \cdot 6$ & $11 \cdot 1-14.5$ & $8.5-17.9$ \\
\hline PUFA ( $\%$ en $)^{*}$ & $6 \cdot 2$ & $2 \cdot 1$ & $5 \cdot 8$ & $4 \cdot 9-7 \cdot 1$ & $3 \cdot 7-9 \cdot 8$ \\
\hline $18: 2 n-6(\mathrm{~g} / \mathrm{d})^{*}$ & 13.4 & $5 \cdot 7$ & $12 \cdot 4$ & $9 \cdot 6-15 \cdot 9$ & $6 \cdot 6-23 \cdot 1$ \\
\hline $20: 4 n-6(\mathrm{mg} / \mathrm{d})^{\star}$ & 93 & 44 & 80 & $60-120$ & $32-180$ \\
\hline $18: 3 n-3(\mathrm{~g} / \mathrm{d})^{*}$ & $1 \cdot 7$ & 0.9 & 1.4 & $1.1-1.9$ & $0.7-3.6$ \\
\hline $20: 5 n-3(\mathrm{mg} / \mathrm{d})^{*}$ & 61 & 65 & 40 & $10-90$ & $0-189$ \\
\hline $22: 6 n-3(\mathrm{mg} / \mathrm{d})^{\star}$ & 110 & 96 & 80 & $40-160$ & $10-299$ \\
\hline Choline (mg/d) & 391 & 101 & 387 & $313-460$ & $246-563$ \\
\hline Vitamin D $(\mu \mathrm{g} / \mathrm{d})$ & 8.0 & 4.4 & $7 \cdot 8$ & $4.5-10.9$ & $1 \cdot 9-16 \cdot 6$ \\
\hline
\end{tabular}

$\%$ en, Percentage of energy.

${ }^{\star}$ Skewed distributions $(P<0.05$; Kolmogorov-Smirnov test). 


\section{Statistical analyses}

All data were analysed using the SPSS statistical software package for Windows (version 19.0; SPSS, Inc.). The results were checked for normal distributions using the KolmogorovSmirnov test. Pearson correlation $r$ and Spearman correlation $\rho$ coefficients, as appropriate, were used to detect significant associations between the intakes of DHA, choline and vitamin D from foods. To address whether fish intake was associated with the intake and biochemical measures of DHA, vitamin D and choline status, we grouped the women by fish (including all finfish and shellfish) as $\leq 75$, 76-149 or $\geq 150 \mathrm{~g} /$ week. Here, one food guide serving of fish in Canada is $75 \mathrm{~g}^{(43)}$. ANOVA followed by Tukey's honest significant difference test was used to detect significant differences in nutrient intakes from foods, and plasma $25(\mathrm{OH}) \mathrm{D}$, plasma free choline, and erythrocyte PE DHA between women grouped by fish intake. Vancouver is at a latitude of $49^{\circ} 16^{\prime}$, with average sunshine of about 64, 56, 60, 85, 134 and $182 \mathrm{~h} /$ month for the 6 months of November to April, respectively, and 231, 229, 294, 268, 199 and $125 \mathrm{~h} / \mathrm{month}$ for the 6 months of May to October, respectively ${ }^{(44)}$. Assuming a half-life of plasma $25(\mathrm{OH}) \mathrm{D}$ formed following sunshine exposure of $14 \mathrm{~d}^{(45)}$, we defined winter and summer as November-April and May-October, respectively, and then compared plasma 25(OH)D concentrations in blood collected in the two seasons using an independent $t$ test. All $P$ values are based on two-sided tests, with a $P<0.05$ considered statistically significant. Values in the text are means unless stated otherwise.

\section{Results}

The age of the 222 women in the present study was $32 \cdot 7$ (SD 5.0) years; $73.4 \%$ were Caucasian, $18.5 \%$ of Asian background, $3 \cdot 1 \%$ of East Indian descent, and the remaining $5.0 \%$ were of other backgrounds. Of these women, nineteen reported that they ate no fish, but did eat meat or poultry, five were lacto-ovo vegetarians and ate no meat, poultry or fish, and one woman ate fish but no meat or poultry. Regardless of the coastal location of Vancouver, $48 \%$ of the women consumed $<150 \mathrm{~g} /$ week of fish, and $41 \%$ consumed $\geq 500 \mathrm{ml} / \mathrm{d}$ of milk. Dietary intakes, as percentage total energy, were normally distributed for carbohydrate, protein, total fat, saturated fatty acids and MUFA, but were skewed to lower median than mean intakes for total PUFA and the individual fatty acids $18: 2 n-6,18: 3 n-3,20: 4 n-6$, EPA and DHA (Table 1). The dietary intakes of total choline and vitamin $\mathrm{D}$ were normally distributed, with mean intakes of $391 \mathrm{mg} / \mathrm{d}$ and $8.0 \mu \mathrm{g} / \mathrm{d}$, respectively (Table 1). Fish intake was also skewed, with a mean of 196 (SD 164; median 156; interquartile range $73-285$; 5 th-95th percentile range $0-522) \mathrm{g} /$ week. The contribution of different foods to the total intake of choline is provided in Table S1.

We first addressed the concordance between the dietary intakes and biochemical measures of status for the nutrients of interest. The dietary intake of DHA was significantly and positively correlated with erythrocyte PE DHA ( $\rho$ o.31,
$P<0.001$; Fig. 1(a)). A similar significant positive association was found between the intake of choline and plasma free choline ( $\rho 0 \cdot 23, P=0 \cdot 001$; Fig. 1(b)). The dietary intake of EPA was also significantly correlated with erythrocyte PE EPA ( $\rho$ 0.48,
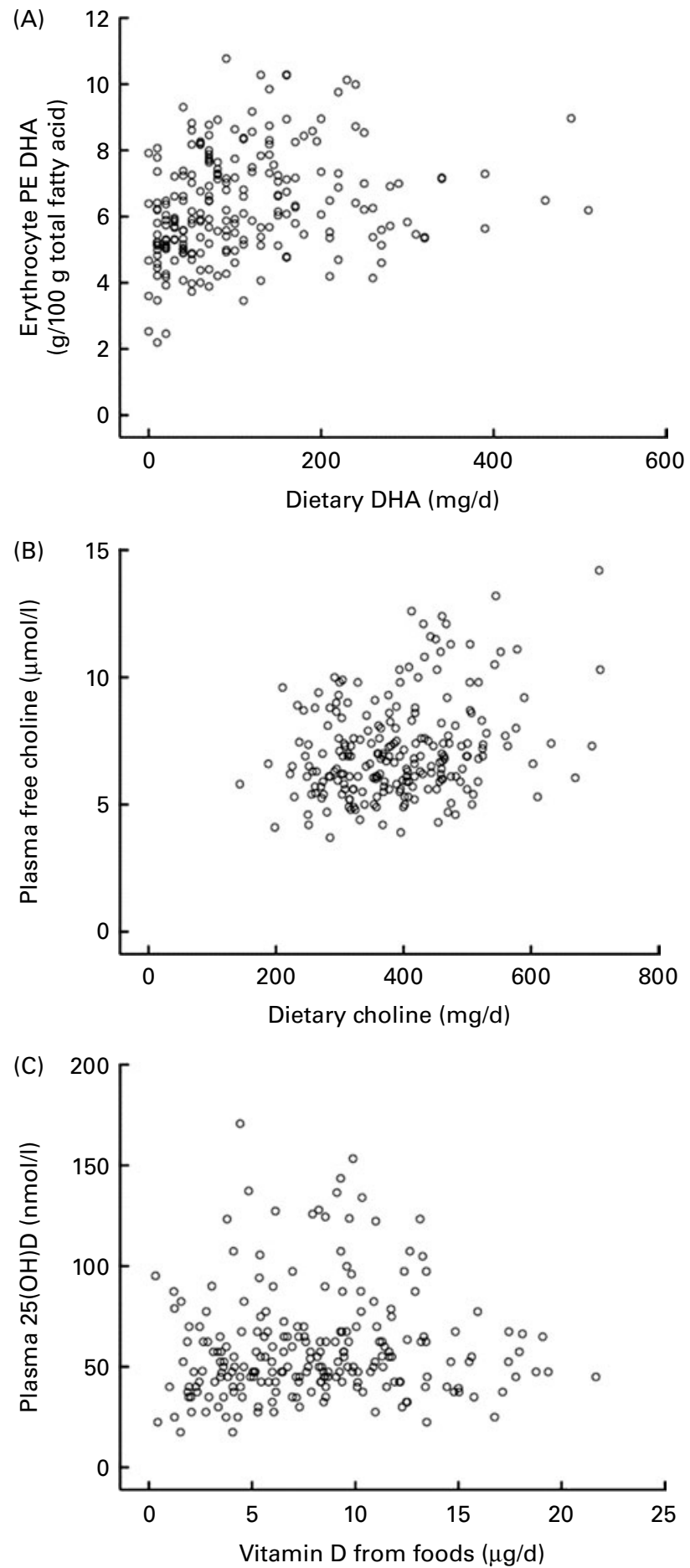

Fig. 1. Scatter plots to show the relationship between dietary intake and biochemical measures of status: (A) DHA intake and erythrocyte phosphatidylethanolamine (PE) DHA $(\rho 0.31, P<0.001)$, (B) choline intake and plasma free choline $(\rho 0.23, P=0.001),(C)$ vitamin $D$ from foods and plasma 25 -hydroxyvitamin $\mathrm{D}(25(\mathrm{OH}) \mathrm{D})(\rho 0.11, P=0.09)$. The results were analysed for pregnant women at 16 weeks' gestation $(n$ 222) using Spearman's $\rho$ correlation analysis. 
$P<0.001$, data not shown). We found only a weak trend between the intake of vitamin $\mathrm{D}$ from foods and plasma 25(OH)D ( $\rho$ 0.11, P=0.09; Fig. 1(c)), and no significant association in the subset of women studied in the winter months ( $\rho 0.05, P=0.61 ; n$ 99). However, plasma $25(\mathrm{OH}) \mathrm{D}$ was lower in women studied in the winter $(54 \cdot 2$ (SD 25.7) nmol/l; $n$ 99) than summer $(63.5$ (SD 27.3) nmol/1; $n$ 123) $(P=0.009)$.

Next, we addressed whether fish intake is associated with the intake and biochemical measures of DHA, choline and vitamin D status. Women consuming $\geq 150 \mathrm{~g} /$ week fish had significantly higher intakes of DHA and higher erythrocyte PE DHA levels, as well as higher choline intakes and plasma free choline concentrations, and higher intakes of vitamin $\mathrm{D}$ from foods and plasma 25(OH)D concentrations than women consuming $\leq 75 \mathrm{~g} /$ week fish $(P<0.05$; Table 2$)$. Because DHA is present in animal lipids other than fish, and fish vary in DHA, we also grouped women by DHA intake as $<50,50-200$ and $>200 \mathrm{mg} / \mathrm{d}$ DHA. Women consuming $>200 \mathrm{mg} / \mathrm{d}$ DHA ( $n$ 35) had significantly higher erythrocyte PE DHA, plasma free choline and 25(OH)D levels than women consuming $<50 \mathrm{mg} / \mathrm{d}$ DHA ( $n$ 63), with erythrocyte PE DHA levels of 6.54 (SD 1.57) and 5.47 (SD 1.31) g/100 g total fatty acid, plasma free choline concentrations of 7.55 (SD 2.31) and 6.61 (SD 1.63) $\mu \mathrm{mol} / \mathrm{l}$, and plasma 25(OH)D concentrations of $64.9(\mathrm{SD} \mathrm{31.4)}$ and $50.9(\mathrm{SD} \mathrm{21.0}) \mathrm{nmol} / \mathrm{l}$, in the two groups, respectively $(P<0.05 ;$ Fig. 2$)$. The erythrocyte PE DHA, plasma free choline and $25(\mathrm{OH}) \mathrm{D}$ concentrations among women consuming 50-200 mg/d DHA ( $n$ 124) were also higher than those of women consuming $<50 \mathrm{mg} / \mathrm{d}$ DHA $(P<0.05$; Fig. 2), but not different from those of women consuming $>200 \mathrm{mg} / \mathrm{d}$ DHA $(P>0.05)$. The dietary patterns among the women in the present study led to significant positive associations between the intakes from foods of DHA and vitamin D $(\rho 0 \cdot 47, P<0 \cdot 001$; Fig. 3(a)), DHA and choline $(\rho 0.32, P<0.001$; Fig. 3(b)), and choline and vitamin $\mathrm{D}(r$ 0.57, $P<0.001$; Fig. 3(c)), with similar significant associations when adjusted for energy intake (data not shown). There were no significant associations between milk and fish intake; the median fish intake was 140 (interquartile range 67-261) and 156 (interquartile range 62-255) g/week among women who drank $<250 \mathrm{ml}(n$ 64) and $>500 \mathrm{ml}$ ( $n$ 92) milk/d (P>0.05).

\section{Discussion}

In the present study, we demonstrate that for a group of healthy pregnant women, fish intake is positively related not only to DHA intake, but also to the intakes of choline and vitamin D from foods. More specifically, women who consumed $\leq 75 \mathrm{~g} /$ week fish had significantly lower plasma free choline and $25(\mathrm{OH}) \mathrm{D}$, as well as lower erythrocyte PE DHA levels than women consuming $\geq 150 \mathrm{~g} /$ week fish $(P<0 \cdot 05)$. When considered based on DHA intake, women consuming $<50 \mathrm{mg} / \mathrm{d}$ DHA appear to be at increased risk of low plasma 25(OH)D and free choline (Fig. 2). Observational studies have shown that maternal fish intakes during gestation are positively associated with child performance in tests of neurodevelopment, attributing the benefits of higher fish intakes to $\mathrm{DHA}^{(14-18)}$. However, intervention studies addressing the possible benefits of maternal DHA supplements on child outcome have yielded mixed results, with several studies finding little evidence of benefit ${ }^{(46-52)}$. While it is clear that DHA plays critical roles in brain development and function $^{(30,53)}$, the present study raises the possibility of confounding nutrient deficiencies by which fish is an important source and necessary for optimal brain development. Whether failure to identify and correct for nutrients other than DHA that may be limiting and constrain child development plays any role in the variable outcomes of studies assessing the benefits of maternal supplementation with DHA during pregnancy is not known. Notably, Helland et al. ${ }^{(49-51)}$ found higher scores on standard tests of cognitive functioning at 4 and 7 years of age among children of Norwegian women given cod liver oil providing $10 \mu \mathrm{g}$ vitamin D, $1183 \mathrm{mg}$ DHA and $803 \mathrm{mg} \mathrm{EPA} / \mathrm{d}$ in pregnancy and lactation when compared to children of women given a corn oil placebo that was balanced to also provide $10 \mu \mathrm{g} / \mathrm{d}$ vitamin D.

Table 2. Dietary intakes from foods and biochemical measures of DHA, choline and vitamin D among Canadian pregnant women at 16 weeks' gestation when grouped by fish intake*

(Mean values and standard deviations)

\begin{tabular}{|c|c|c|c|c|c|c|c|c|}
\hline & \multicolumn{8}{|c|}{ Fish intake (g/week) } \\
\hline & \multicolumn{2}{|c|}{ All women (n 222) } & \multicolumn{2}{|c|}{$\leq 75(n 56)$} & \multicolumn{2}{|c|}{$76-149(n 50)$} & \multicolumn{2}{|c|}{$\geq 150(n 116)$} \\
\hline & Mean & SD & Mean & SD & Mean & SD & Mean & SD \\
\hline \multicolumn{9}{|l|}{ Dietary intake } \\
\hline $\mathrm{DHA}(\mathrm{mg} / \mathrm{d})$ & 110 & 96 & $28^{\mathrm{a}}$ & 19 & $65^{\mathrm{b}}$ & 26 & $171^{\mathrm{c}}$ & 94 \\
\hline Total choline (mg/d) & 391 & 101 & $353^{a}$ & 91 & $392^{\mathrm{b}}$ & 96 & $408^{\mathrm{b}}$ & 104 \\
\hline Vitamin $D(\mu \mathrm{g} / \mathrm{d})$ & 8.0 & 4.4 & $6 \cdot 3^{a}$ & 3.9 & $7 \cdot 1^{\mathrm{a}}$ & 3.9 & $9 \cdot 3^{b}$ & 4.4 \\
\hline \multicolumn{9}{|l|}{ Biochemical measures } \\
\hline Erythrocyte PE DHA (g/100 g total fatty acid) & $6 \cdot 31$ & 1.60 & $5 \cdot 25^{\mathrm{a}}$ & 1.27 & $6 \cdot 29^{\mathrm{b}}$ & $1 \cdot 30$ & $6 \cdot 83^{\mathrm{c}}$ & 1.62 \\
\hline Plasma free choline $(\mu \mathrm{mol} / \mathrm{l})$ & $7 \cdot 15$ & 1.90 & $6 \cdot 59^{\mathrm{a}}$ & 1.65 & $7 \cdot 21^{\mathrm{a}, \mathrm{b}}$ & $1 \cdot 72$ & $7 \cdot 40^{\mathrm{b}}$ & 2.05 \\
\hline Plasma $25(\mathrm{OH}) \mathrm{D}(\mathrm{nmol} / \mathrm{l})$ & $59 \cdot 3$ & 26.9 & $50 \cdot 3^{\mathrm{a}}$ & $20 \cdot 0$ & $62 \cdot 3^{\mathrm{b}}$ & 24.5 & $62 \cdot 5^{\mathrm{b}}$ & 29.8 \\
\hline
\end{tabular}

PE, phosphatidylethanolamine; 25(OH)D, 25-hydroxyvitamin D.

a,b,c Mean values within a row with unlike superscript letters were significantly different $(P<0.05$; ANOVA, post hoc Tukey's honest significant difference test).

${ }^{*}$ Fish includes all finfish and shellfish. 
An important question is the extent to which the diets of the women in our study are representative of other women following westernised diets. Despite the coastal location of Vancouver, $48 \%$ of the women ate $<150 \mathrm{~g} /$ week fish and $83 \%$ consumed $<200 \mathrm{mg} / \mathrm{d}$ DHA, which is the intake recommended during pregnancy and lactation in the $2008 \mathrm{FAO} /$ WHO consultation on fats and fatty acids in human nutrition ${ }^{(53)}$. The mean intake $110 \mathrm{mg} / \mathrm{d}$ DHA among the women in our study is similar to the mean intakes of DHA among pregnant women in other countries following westernised diets ${ }^{(53)}$. Relatively little information is as yet available on dietary choline intakes, which in the present study was 391 (SD 101) $\mathrm{mg} / \mathrm{d}$ and similar to the choline intake of 409 (SD 179) $\mathrm{mg} / \mathrm{d}$ reported for pregnant women in the USA ${ }^{(54)}$. The current adequate intake for choline during pregnancy is $450 \mathrm{mg} / \mathrm{d}^{(55)}$, which infers that a considerable proportion of women may be at risk of poor choline status. Further, women in the present study who consumed
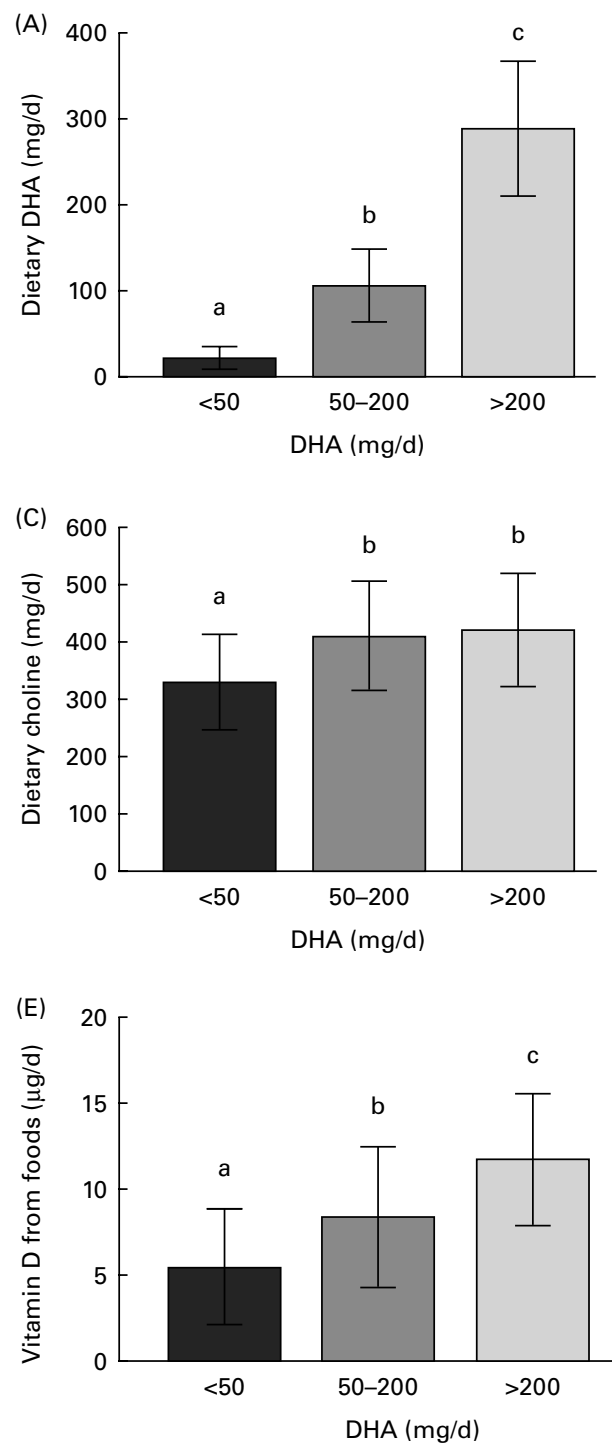

Fig. 2. Differences in dietary intakes $(A, C$ and $E$ ) and biochemical measures $(B, D$ and $F)$ of $D H A$, choline and vitamin $D$ status among pregnant women grouped by DHA intake as $<50$ ( $n$ 62), 50-200 ( $n$ 125), or $>200 \mathrm{mg} / \mathrm{d}(n 35)$. Values are means, with standard deviations represented by vertical bars. ${ }^{\text {a,b,c }}$ Mean values with unlike superscript letters were significantly different $(P<0.05$; ANOVA, post hoc Tukey's honest significant difference test). $P E$, phosphatidylethanolamine; 25(OH)D, 25-hydroxyvitamin D.

$<450(n$ 157) or $\geq 450(n$ 65) $\mathrm{mg} / \mathrm{d}$ choline had DHA intakes of 95 (SD 94) and 146 (SD 92) $\mathrm{mg} / \mathrm{d}$, and vitamin D intakes from foods of 6.7 (SD 3.7) and $11.2(\mathrm{SD} 4.19) \mu \mathrm{g} / \mathrm{d}(P<0.05)$. However, we note that as yet there is no evidence that maternal plasma choline concentrations in gestation are related to later measures of child intelligence quotient (IQ) ${ }^{(56)}$.

The present study was not designed to assess vitamin D insufficiency or the efficacy of food fortification or vitamin supplements in maintaining acceptable plasma 25(OH)D concentrations during pregnancy. However, the present study confirms and reinforces the high prevalence of vitamin D insufficiency among Canadian pregnant women, as well as other adults and children ${ }^{(21,24,57-59)}$. Uncertainty over the optimal plasma $25(\mathrm{OH}) \mathrm{D}$ during pregnancy remains, with a concentration $\geq 50 \mathrm{nmol} / 1$ recommended in the most recent dietary reference intake ${ }^{(60)}$, and $\geq 75 \mathrm{nmol} / 1$ considered sufficient for pregnant and lactating women by the Canadian Pediatric
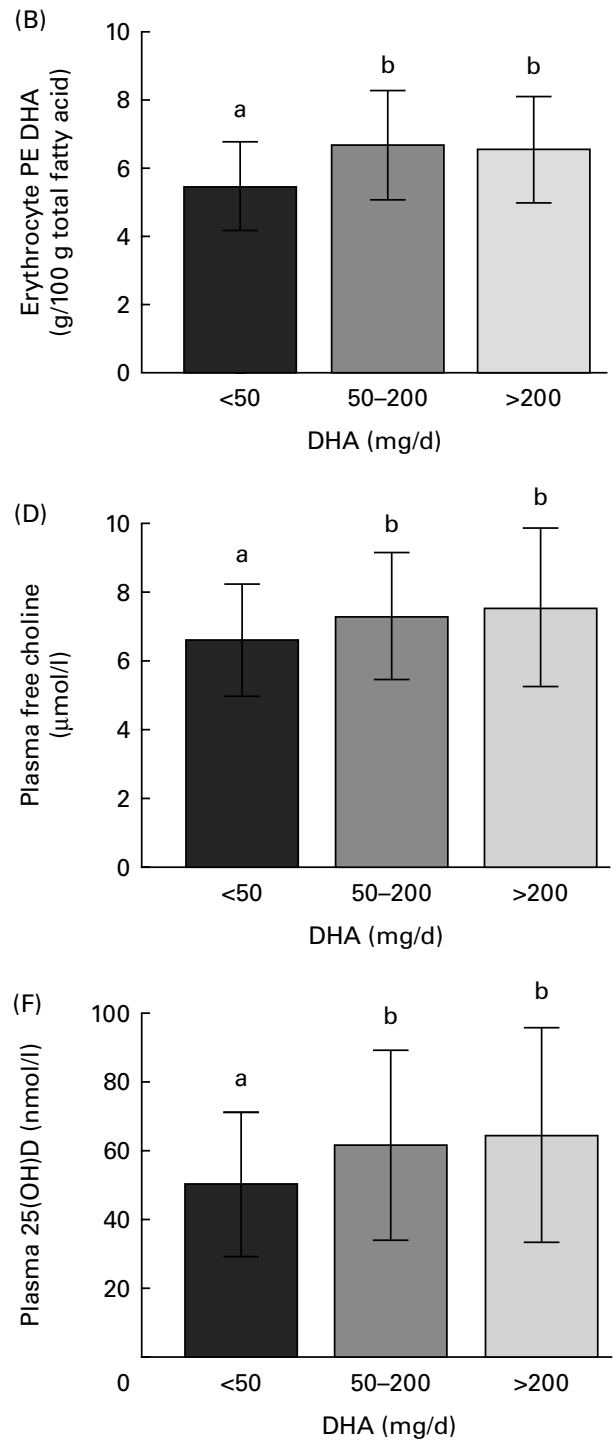

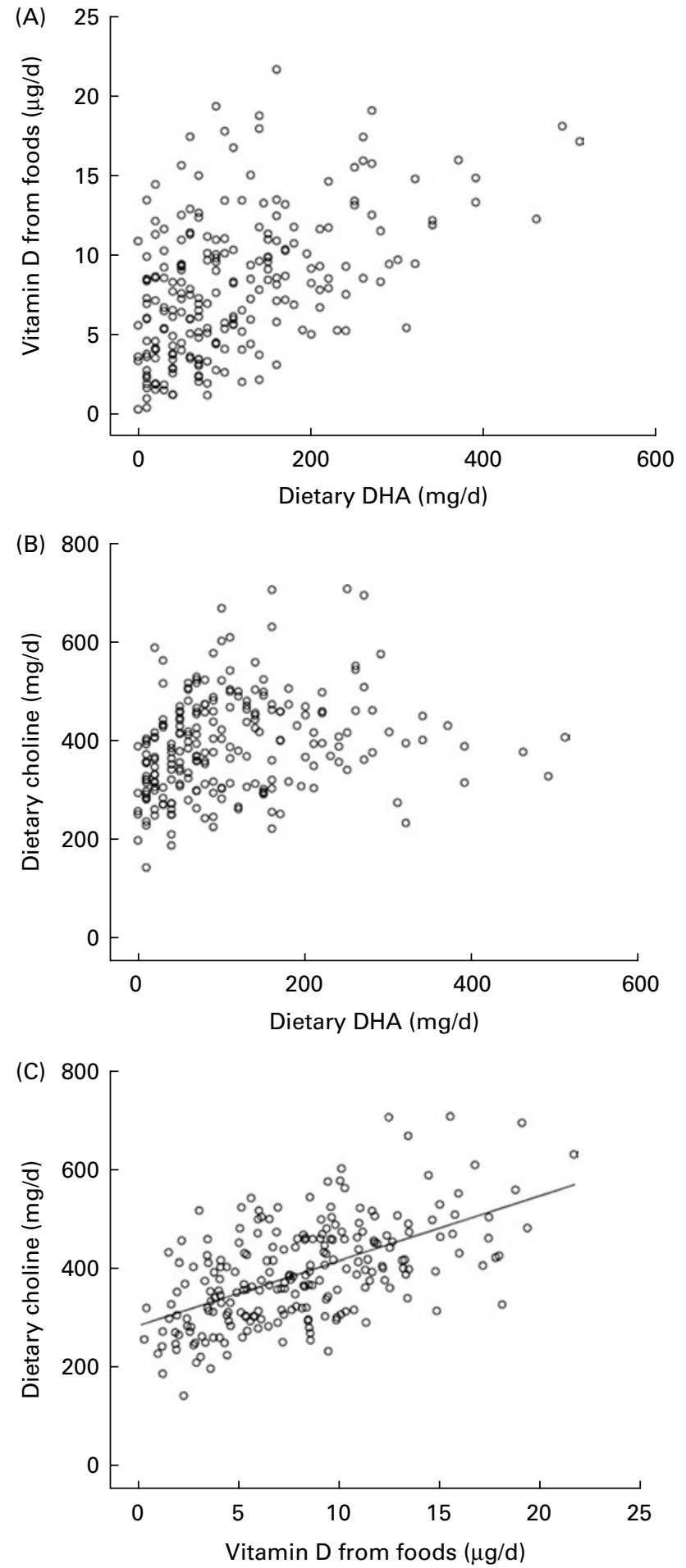

Fig. 3. Scatter plots to show the relationship between the dietary intakes: $(A)$ DHA and vitamin $D$ from foods $(\rho 0.47, P<0.001)$, (B) DHA and choline ( $\rho$ 0.32, $P<0.001)$, (C) choline and vitamin $\mathrm{D}$ from foods $(r 0.57, P<0.001)$. The results were analysed for pregnant women $(n$ 222) using Spearman's $\rho$ correlation analysis and Pearson correlation analysis.

Society ${ }^{(61)}$. We found that 88 and $76 \%$ of the women in our study had a plasma $25(\mathrm{OH}) \mathrm{D}<75 \mathrm{nmol} / 1$ in the winter and summer, respectively, and three women in the winter and one woman in the summer had a plasma $25(\mathrm{OH}) \mathrm{D}<25 \mathrm{nmol} / \mathrm{l}$.
The apparently high prevalence of $25(\mathrm{OH}) \mathrm{D}$ insufficiency occurred despite the high proportion (40\%) of women in our study who consumed $>500 \mathrm{ml} / \mathrm{d}$ milk, contributing to a theoretical $5.5 \mu \mathrm{g} / \mathrm{d}$ vitamin D. Another recent cross-sectional study found that $72 \%$ of women at 20-27 weeks' gestation in Vancouver had a plasma $25(\mathrm{OH}) \mathrm{D}<75 \mathrm{nmol} / \mathrm{l}^{(21)}$, while the serum $25(\mathrm{OH}) \mathrm{D}$ of non-native pregnant women in the Inuvik zone of the Northwest Territories was $59 \cdot 8$ (SD 29.4) nmol/ $\mathrm{l}^{(24)}$. As in other studies ${ }^{(23,57,62)}$, the significant effect of season on plasma $25(\mathrm{OH}) \mathrm{D}$ levels found in our study shows that environmental factors make an impact on vitamin D status, over and above the effect of food fortification or vitamin supplements. Also consistent with other studies ${ }^{(23,62)}$, we found a lack of association between total vitamin $\mathrm{D}$ intake from foods and plasma 25(OH)D. Several reasons could explain this. First, we did not quantify the contribution of vitamin D from vitamin supplements. We also estimated vitamin D intakes from foods with the assumption of a standard, consistent vitamin D fortification in milk, which in practice may be highly variable ${ }^{(63,64)}$. Regardless, our results to show that women consuming $>75 \mathrm{~g}$ fish/week had higher plasma $25(\mathrm{OH}) \mathrm{D}$ concentrations than women with lower fish intakes, suggests that natural food sources of vitamin D may be more effective in promoting higher vitamin D status than supplemental sources of the vitamin. Consistent with this, women in Japan who consumed fish $\geq 4$ times/week had a significantly higher plasma $25(\mathrm{OH}) \mathrm{D}$ levels than those consuming fish $1-3$ times/week $^{(65)}$.

In summary, the present study has shown that among Canadian pregnant women, those women consuming $\geq 2$ servings of fish/week have higher intakes of DHA, as well as choline and vitamin D, and higher biochemical markers of DHA, choline and vitamin $\mathrm{D}$ than women consuming $\leq 1$ serving fish/week. While fish is well recognised as an important source of DHA, our study highlights the contribution of fish to other nutrients also needed for brain development. This study highlights the possibility that intervention with single nutrients, such as DHA, may achieve null findings of benefit if supplementation is in populations or individuals in whom other key nutrients that make an impact on the outcome of interest are also limiting.

\section{Acknowledgements}

The authors would like to acknowledge the financial support from the Canadian Institutes of Health Research (CIHR). S. M. I. designed the research. R. A. D. and D. J. K. conducted the laboratory analyses. B. T. W. analysed the dietary data. S. M. I. and B. T. W. analysed the data and wrote the manuscript. S. M. I. had primary responsibility for the final content. All authors read and approved the final manuscript. There is no conflict of interest for any of the authors.

The supplementary material for this article can be found at http://www.journals.cambridge.org/bjn

\section{References}

1. Barberger-Gateau P, Letenneur L, Deschamps V, et al. (2002) Fish, meat, and risk of dementia: cohort study. BMJ $\mathbf{3 2 5}$ 932-933. 
2. Barberger-Gateau P, Raffaitin C, Letenneur L, et al. (2007) Dietary patterns and risk of dementia: the Three-City cohort study. Neurology 69, 1921-1930.

3. Daviglus ML, Stamler J, Orencia A, et al. (1997) Fish consumption and the 30-year risk of fatal myocardial infarction. N Engl J Med 336, 1046-1053.

4. Hibbeln JR, Nieminen LR, Blasbalg TL, et al. (2006) Healthy intakes of $n-3$ and $n-6$ fatty acids: estimations considering worldwide diversity. Am J Clin Nutr 83, Suppl. 6, 1483S-1493S.

5. Huang TL, Zandi PP, Tucker KL, et al. (2005) Benefits of fatty fish on dementia risk are stronger for those without APOE epsilon4. Neurology 65, 1409-1414.

6. Kromhout D, Bosschieter EB \& de-Lezenne-Coulander C (1985) The inverse relation between fish consumption and 20-year mortality from coronary heart disease. $N$ Engl J Med 312, 1205-1209.

7. Kromhout D, Feskens EJ \& Bowles CH (1995) The protective effect of a small amount of fish on coronary heart disease mortality in an elderly population. Int J Epidemiol $\mathbf{2 4}$ $340-345$.

8. Morris MC, Evans DA, Bienias JL, et al. (2003) Consumption of fish and $n-3$ fatty acids and risk of incident Alzheimer disease. Arch Neurol 60, 940-946.

9. Morris MC, Evans DA, Tangney CC, et al. (2005) Fish consumption and cognitive decline with age in a large community study. Arch Neurol 62, 1849-1853.

10. Shekelle RB, Missell L \& Paul O (1985) Fish consumption and mortality from coronary heart disease. $N$ Eng J Med 313, 820 .

11. Jump DB, Botolin D, Wang Y, et al. (2008) Docosahexaenoic acid (DHA) and hepatic gene transcription. Chem Phys Lipids 153, 3-13.

12. Li GR, Sun HY, Zhang XH, et al. (2009) Omega-3 polyunsaturated fatty acids inhibit transient outward and ultra-rapid delayed rectifier $\mathrm{K}^{+}$currents and $\mathrm{Na}^{+}$current in human atrial myocytes. Cardiovasc Res 81, 286-293.

13. Serhan CN \& Chiang N (2008) Endogenous pro-resolving and anti-inflammatory lipid mediators: a new pharmacologic genus. Br J Pharmacol 153, Suppl. 1, S200-S215.

14. Boucher O, Burden MJ, Muckle G, et al. (2011) Neurophysiologic and neurobehavioral evidence of beneficial effects of prenatal omega-3 fatty acid intake on memory function at school age. Am J Clin Nutr 93, 1025-1037.

15. Daniels JL, Longnecker MP, Rowland AS, et al. (2004) Fish intake during pregnancy and early cognitive development of offspring. Epidemiology 15, 394-402.

16. Hibbeln JR, Davis JM, Steer C, et al. (2007) Maternal seafood consumption in pregnancy and neurodevelopmental outcomes in childhood (ALSPAC study): an observational cohort study. Lancet 369, 578-585.

17. Mendez MA, Torrent M, Julvez J, et al. (2009) Maternal fish and other seafood intakes during pregnancy and child neurodevelopment at age 4 years. Public Health Nutr 12, $1702-1710$.

18. Oken E, Østerdal ML, Gillman MW, et al. (2008) Associations of maternal fish intake during pregnancy and breastfeeding duration with attainment of developmental milestones in early childhood: a study from the Danish National Birth Cohort. Am J Clin Nutr 88, 789-796.

19. Bodnar LM \& Simhan HN (2010) Vitamin D may be a link to black-white disparities in adverse birth outcomes. Obstet Gynecol Surv 65, 273-284.

20. Brannon PM \& Picciano MF (2011) Vitamin D in pregnancy and lactation in humans. Annu Rev Nutr 31, 89-115.
21. Li W, Green TJ, Innis SM, et al. (2011) Suboptimal vitamin D levels in pregnant women despite supplement use. Can J Public Health 102, 308-312.

22. McGowan CA, Byrne J, Walsh J, et al. (2011) Insufficient vitamin D intakes among pregnant women. Eur J Clin Nutr $\mathbf{6 5}$, 1076-1078.

23. Vieth R, Cole DE, Hawker GA, et al. (2001) Wintertime vitamin D insufficiency is common in young Canadian women, and their vitamin D intake does not prevent it. Eur J Clin Nutr 55, 1091-1097.

24. Waiters B, Godel JC \& Basu TK (1999) Perinatal vitamin D and calcium status of northern Canadian mothers and their newborn infants. J Am Coll Nutr 18, 122-126.

25. Fleischman AR, Rosen JF, Cole J, et al. (1980) Maternal and fetal serum 1,25-dihydroxyvitamin D levels at term. J Pediatr 97, 640-642.

26. Eyles DW, Feron F, Cui X, et al. (2009) Developmental vitamin D deficiency causes abnormal brain development. Psychoneuroendocrinology 34, Suppl. 1, S247-S257.

27. Kesby JP, Cui X, O'Loan J, et al. (2010) Developmental vitamin $\mathrm{D}$ deficiency alters dopamine-mediated behaviors and dopamine transporter function in adult female rats. Psychopharmacology (Berl) 208, 159-168.

28. Eyles D, Burne T \& McGrath J (2011) Vitamin D in fetal brain development. Semin Cell Dev Biol 22, 629-636.

29. O'Loan J, Eyles DW, Kesby J, et al. (2007) Vitamin D deficiency during various stages of pregnancy in the rat; its impact on development and behaviour in adult offspring. Psychoneuroendocrinology 32, 227-234.

30. Bazan NG, Musto AE \& Knott EJ (2011) Endogenous signaling by omega-3 docosahexaenoic acid-derived mediators sustains homeostatic synaptic and circuitry integrity. Mol Neurobiol 44, 216-222.

31. Niculescu MD \& Zeisel SH (2002) Diet, methyl donors and DNA methylation: interactions between dietary folate, methionine and choline. J Nutr 132, Suppl. 8, 2333S-2335S.

32. Zeisel SH \& Blusztajn JK (1994) Choline and human nutrition. Annu Rev Nutr 14, 269-296.

33. Al MD, van Houwelingen AC, Kester AD, et al. (1995) Maternal essential fatty acid patterns during normal pregnancy and their relationship to the neonatal essential fatty acid status. Br J Nutr 74, 55-68.

34. Elias SL \& Innis SM (2001) Infant plasma trans, $n-6$, and $n-3$ fatty acids and conjugated linoleic acids are related to maternal plasma fatty acids, length of gestation, and birth weight and length. Am J Clin Nutr 73, 807-814.

35. Friesen RW, Novak EM, Hasman D, et al. (2007) Relationship of dimethylglycine, choline, and betaine with oxoproline in plasma of pregnant women and their newborn infants. J Nutr 137, 2641-2646.

36. Zeisel SH \& Niculescu MD (2006) Perinatal choline influences brain structure and function. Nutr Rev 64, 197-203.

37. Innis SM \& Elias SL (2003) Intakes of essential $n-6$ and $n-3$ polyunsaturated fatty acids among pregnant Canadian women. Am J Clin Nutr 77, 473-478.

38. Friesen RW \& Innis SM (2009) Dietary arachidonic acid to EPA and DHA balance is increased among Canadian pregnant women with low fish intake. J Nutr 139, 2344-2350.

39. Health Canada (2005) Addition of vitamins and minerals to foods. http://www.hc-sc.gc.ca/fn-an/nutrition/vitamin/fortifi cation_final_doc_1-eng.php\#c6

40. U.S. Department of Agriculture (2008) USDA database for the choline content of common foods, Release two. http:// www.nal.usda.gov/fnic/foodcomp/Data/Choline/Choln02.pdf (accessed September 2011). 
41. Popp-Snijders C, Schouten JA, de Jong AP, et al. (1984) Effect of dietary cod-liver oil on the lipid composition of human erythrocyte membranes. Scand J Clin Lab Invest 44, 39-46.

42. Innis SM \& Hasman D (2006) Evidence of choline depletion and reduced betaine and dimethylglycine with increased homocysteine in plasma of children with cystic fibrosis. J Nutr 136, 2226-2231.

43. Health Canada (2010) Food and nutrition: Canada's food guide. http://www.hc-sc.gc.ca/fn-an/food-guide-aliment/indexeng.php

44. Environment Canada (2011) National climate data and information archive. http://climate.weatheroffice.gc.ca/climate

45. Jones G (2008) Pharmokinetics of vitamin D toxicity. Am J Clin Nutr 88, 582S-586S.

46. Campoy C, Escolano-Margarit MV, Ramos R, et al. (2011) Effects of prenatal fish-oil and 5-methyltetrahydrofolate supplementation on cognitive development of children at $6.5 \mathrm{y}$ of age. Am J Clin Nutr 94, Suppl. 6, 1880S-1888S.

47. Dunstan JA, Simmer K, Dixon G, et al. (2008) Cognitive assessment of children at age 2(1/2) years after maternal fish oil supplementation in pregnancy: a randomised controlled trial. Arch Dis Child Fetal Neonatal Ed 93, F45-F50.

48. Escolano-Margarit MV, Ramos R, Beyer J, et al. (2011) Prenatal DHA status and neurological outcome in children at age 5.5 years are positively associated. J Nutr 141, 1216-1223.

49. Helland IB, Saugstad OD, Smith L, et al. (2001) Similar effects on infants of $n-3$ and $n-6$ fatty acids supplementation to pregnant and lactating women. Pediatrics 108, E82.

50. Helland IB, Smith L, Saarem K, et al. (2003) Maternal supplementation with very-long-chain $n$-3 fatty acids during pregnancy and lactation augments children's IQ at 4 years of age. Pediatrics 111, e39-e44.

51. Helland IB, Smith L, Blomén B, et al. (2008) Effect of supplementing pregnant and lactating mothers with $n-3$ very-longchain fatty acids on children's IQ and body mass index at 7 years of age. Pediatrics 122, e472-e 479 .

52. Tofail F, Kabir I, Hamadani JD, et al. (2006) Supplementation of fish-oil and soy-oil during pregnancy and psychomotor development of infants. J Health Popul Nutr 24, 48-56.

53. Brenna JT \& Lapillonne A (2009) Background paper on fat and fatty acid requirements during pregnancy and lactation. Ann Nutr Metab 55, 97-122.
54. Shaw GM, Carmichael SL, Yang W, et al. (2004) Periconceptional dietary intake of choline and betaine and neural tube defects in offspring. Am J Epidemiol 160, 102-109.

55. Institute of Medicine \& National Academy of Sciences (1998) Dietary Reference Intakes for Thiamin, Riboflavin, Niacin, Vitamin $B_{6}$, Folate, Vitamin $B_{12}$, Pantothenic Acid, Biotin, and Choline. Washington, DC: The National Academies Press.

56. Signore C, Ueland PM, Troendle J, et al. (2008) Choline concentrations in human maternal and cord blood and intelligence at 5 y of age. Am J Clin Nutr 87, 896-902.

57. Baraké R, Weiler H, Payette H, et al. (2010) Vitamin D supplement consumption is required to achieve a minimal target 25-hydroxyvitamin $\mathrm{D}$ concentration of $>$ or $=75 \mathrm{nmol} / \mathrm{L}$ in older people. J Nutr 140, 551-556.

58. Whiting SJ, Langlois KA, Vatanparast H, et al. (2011) The vitamin D status of Canadians relative to the 2011 Dietary Reference Intakes: an examination in children and adults with and without supplement use. Am J Clin Nutr 94, $128-135$.

59. Vatanparast H, Calvo MS, Green TJ, et al. (2010) Despite mandatory fortification of staple foods, vitamin D intakes of Canadian children and adults are inadequate. J Steroid Biochem Mol Biol 121, 301-303.

60. Institute of Medicine, Food and Nutrition Board (2010) Dietary Reference Intakes for Calcium and Vitamin D. Washington, DC: National Academy Press.

61. Canadian Paediatric Society (2007) Vitamin D supplementation: recommendations for Canadian mothers and infants. Paediatr Child Health 12, 583-598.

62. Tangpricha V, Pearce EN, Chen TC, et al. (2002) Vitamin D insufficiency among free-living healthy young adults. Am $J$ Med 112, 659-662.

63. Calvo MS, Whiting SJ \& Barton CN (2004) Vitamin D fortification in the United States and Canada: current status and data needs. Am J Clin Nutr 80, Suppl. 6, 1710S-1716S.

64. Faulkner H, Hussein A, Foran M, et al. (2000) A survey of vitamin A and D contents of fortified fluid milk in Ontario. J Dairy Sci 83, 1210-1216.

65. Nakamura K, Nashimoto M, Hori Y, et al. (2000) Serum 25-hydroxyvitamin D concentrations and related dietary factors in peri- and postmenopausal Japanese women. Am J Clin Nutr 71, 1161-1165. 